\title{
Research on MIS Design for Real Estate Company
}

\author{
Zilei Liu \\ Business School, University of Shanghai for Science and Technology \\ Shanghai, China \\ Li Chen (Corresponding author) \\ Business School, University of Shanghai for Science and Technology \\ Shanghai, China, 200093 \\ E-mail: xr_zhang_usst@hotmail.com
}

Received: July 7, 2011 Accepted: August 23, 2011 doi:10.5430/rwe.v2n2p50

\begin{abstract}
Real estate investment and construction projects have the characteristics of large-scale, long life cycle, technical complexity, multi-units involvement, difficult to organize and implement, and the projects are usually located in wide range. Therefore, it's necessary to construct the corresponding project management information system to manage the real estate project timely and accurately, to provide managers sufficient information and decision supports. This paper analyzes the process of real estate construction projects and the projects' information system needs. Based on the analysis, the real estate construction project management information system functions framework and principles of implementation are discussed. Providing real estate development and construction companies with information management supporting tools.
\end{abstract}

Keywords: Real Estate, Project Management, Management Information System

\section{Introduction}

The real estate industry is one of China's pillar industries, the real estate industry's prosperity and stability means a lot to the stable operation of the entire national economy and development. Meanwhile, the real estate industry is also recognized as a long chain industry with huge data, long investment cycle, high degree of uncertainty and risky industry. Real estate investment and construction projects have the characteristics of large-scale, long life cycle, technical complexity, multi-units involvement, difficult to organize and implement, and the projects are usually located in wide range. All these characteristics resulting in the management of real estate construction projects face many difficulties and challenges, such as a many different types of information, frequently communication and difficult to manage.

Recent years, there are some quality accidents in China's real estate industry, such as " Crunchy House " and " Leading House ", and October 2010, in Beijing Daxing Area, one of the buildings under construction was demolished and redevelopment due to quality problems. These problems cached great attention of residents and government. One of the reasons these events happened is that these projects lack of scientific, rigorous, advanced project management ideas and effective project management information system.

Meanwhile, under new market policy of China's real estate, government regulations of real estate development are further increased. Construction land use right transfer gradually standardized, the land use right proportion in total construction costs is gradually increased. Real estate development companies now are difficult to use their "land bank" and enjoy the land value-added benefits; companies increasingly rely on the real estate development investment to get income. Project cost increasing and low profit margins; will be one of the main features of the market. This means that, in order to sustained, get rapid and healthy development, real estate development companies need to pursue economies of scale, and implement sophisticated management. Multi-project development and implement greatest possible added value policy will become an inevitable choice for enterprises to become bigger and stronger. But, the multi-project development and management is often with the problems of low efficiency, high target error rate, and especially the problem of planning cost and target profits. In order to achieve high output with less input, real estate companies has to make a complex project development process into the process can be controlled, need to coordinated, efficient allocation of capital, increase capital and the effective utilization of scarce resources to protect the effective communication among headquarters and different business units, and thus to predict and analysis the capital, cost, schedule, sales and other issues and reduce the possible risks. 
In this context, the real estate development companies need to construct a project management information system line with China's national conditions and real estate development for the provision of modern information and support decision making to take full advantage of information resources, and realize scientific management of real estate business, improve operational effectiveness and efficiency of real estate projects and enhance the core competitiveness of the real estate business.

\section{Analysis of Real Estate Construction Project Process and the Needs of IS}

When the real estate development project come into the building construction phase, it needs to have great control over quality, cost and time: as a technical specification, quality is the most basic technical conditions to achieve the project's functions, while the changes of cost and schedule will also affect the development project's economic benefits directly. Therefore, in order to achieve the desired economic benefits, real estate development companies focus on the project quality objectives under certain conditions, and the most important is to control the cash flow. That means the decision-making process of project income, expenses and the corresponding timing to form the project development plan, and control the project based on this standard process. The main flows of real estate construction projects are shown in Figure 1:

As the real estate construction projects have long construction period, many participants, and large span space, so the building needs on information system for real estate construction has the following characteristics:

\subsection{Long Period of Data Collection}

The real estate industry products like the ordinary standards, procedures, products, which is determined by the project itself. And a real estate development projects, ranging from three to five years, as many as last year or more, which makes project-centric data collection (information flow) a longer period.

\subsection{Spatial Characteristics of Data}

Real estate construction management information system not only attribute data, a large number of spatial data, And between these two data inextricably linked. This established model to the database, the link between attribute and graphic data and the transfer mode and the choice of spatial data structures more difficult.

$$
<\text { Figure } 1 \text { about here }>
$$

\subsection{Data Diversity}

Real estate construction project management information system data, forms and more users and more variety, collection sites were scattered and diverse processing complex situation. Project data is usually by different project participants. Project participants involved in the project time, the internal organization and communication of information in different ways, Likely to cause a certain degree of disorder information organization, the project data leakage, data loss, incomplete data, data destruction, etc., thereby affecting the smooth implementation of the project. In addition, a stage or a party in the data provided will usually be at a later stage, or other participants use, and different parties involved data acquisition and processing channels, in different ways, resulting in a large number of duplicate data entry and distortion, a serious impediment to the smooth transfer of data, sharing and appreciation.

\subsection{Many Functional Subsystems}

Real estate construction and management information systems covering a wide range of complex business processes, which include the construction of the project organization and supervision, financial management, schedule management, contract management. Therefore, the number of its many subsystems, such as: geographic information systems (GIS), CAD building information systems, property management systems Office Automation (ROA), real estate construction contract management system (RCMS) and so on.

\section{Real Estate Construction Project Management Information System Functional Framework Design}

Real estate construction projects in the process of schedule, cost, quality management is critical. Therefore, in the design of management information systems, should schedule control, cost control, cost control and quality engineering as its core control subsystem.

The following are the three core subsystems of the design

Schedule control sub-system design: Real estate projects in the early, must be based on market conditions, sources of funding, the ability of construction enterprises in the construction, construction management and other factors, reasonable arrangements for project construction schedule. During the construction process, the main task of the subsystem is in strict accordance with construction plans to monitor the progress of the construction project. Meanwhile, the subsystem must be able to immediately reflect the developers, project supervision, construction units, and many 
other sources of information in order to achieve optimal control of the project works. Towel in the progress of the project process, the subsystem can live funds, the allocation of resources, staff scheduling and other management activities to provide effective decision support. Subsystem must also be able to progress the construction of uncertainty to predict and determine the appropriate response options. Progress of the control subsystem to achieve the design requirements: In the process of project implementation, to various stages of the project work content, workflow, when asked about continuing the logical relationship between activities in the preparation and optimization scheme and implemented, while implementation of the plan process, to continue to check the actual schedule and project plan deviations, if deviation, to be able to analyze the reasons for the deviation, and guide users to take appropriate remedial measures, to adjust or modify the original plan, and ultimately solve problems.

Cost control subsystem design: This subsystem runs through the whole process of real estate projects, real estate construction project management information system in the most critical part. Its main purpose is to reflect the dynamic process of the project and the investment costs and project profitability and ensure financial enterprises in the correct decision. Early in the project, the main function of the subsystem: the process of calculation of project resources consumption and the resulting costs, according to the company's cost of financing, market conditions, to predict the profitability of the project: the process of establishing the project activities in time and resources on the correspondence between the analysis and prediction of project costs in the distribution process of the project; build project sales planning, analysis, project income in the distribution process of the project; computing projects on technical and economic evaluation, and the formation of project construction control plans, and key control indicators. In the project construction phase, the subsystem's main task is to project the costs that occur during the dynamic monitoring and effective control of the actual cost of the project and the project budget to make it consistent. Upon completion of the project, statistics on actual project costs, revenue, cash flow of data, and comparative analysis of the initial plans for future projects to improve and optimize decision-making. Cost control subsystem design requirements: the cost of real estate projects for the control object to the project site as the basic unit to sub-project as the basic unit of cost control, cost database support, in the tender, sign contract, the various stages of construction and property management, according to different levels when the line cost planning, accounting, analysis, tracking and feedback, support costs and reduce the cost of making forecasts, the premise of guaranteeing quality objectives as far as cost savings. But real estate is subject to many factors, such as the impact of policy factors may be required to pursue progress, which is bound to result in increased costs. Therefore, cost control subsystem will make full use of the value of the project cost plan and actual consumption value to the project implementation tracking the effect of detection and timely analysis of cost performance, early detection of cost differences in the out of control in time to take corrective measures.

Quality control subsystem design: Project quality control based on the main project contract, design documents, technical specifications prescribed standards, such as the various design specifications issued by the state, rules, regulations, standards; construction and acceptance; construction and installation of quality inspection and assessment standards; quality building materials Atlas of standard and other relevant technical standards. During the construction process, the main task of the subsystem is in strict accordance with construction plans to monitor the quality of the project. In addition, the quality of subsystem construction must also be able to predict the uncertainty factors, and determine the appropriate response options. Quality control subsystem design requirements: the project implementation process operations and activities under constant inspection, measurement and evaluation to determine whether consistent with the relevant quality standards, if not match, then find a cause, development of improvement programs, and ultimately achieve quality objectives and requirements.

In addition to these three main subsystems, real estate, construction project management information system should also be generated in the process of project construction contract for the management, document approval flow, and meet all of the office automation project requirements, so comprehensive above, real estate construction project management information system functional framework shown in <Figure 2 about here>

\section{Principles of Implementing Real Estate Construction Project Management Information System}

Real estate construction project management with the actual situation in the real estate construction project management information system implementation process, should adhere to the following main principles:

\subsection{Functional Principle}

System function scalability and ease of maintenance: on the one hand the scale of the whole system should be scalable, on the other hand to make the system easy to maintain, according to the user's requirements easily extensions. Towel set with remote office and control functions: real estate project management information system using the sites are widely distributed, and may be far apart. These features will require in the real estate project management information system development and design should fully take into account the requirements of long-distance communications, especially in 
today's global economic integration, multinational operations will become increasingly common, which requires us to develop design system should make full use of network technology to meet the needs of users.

\section{2 Principle of Reliability}

In real estate construction projects, the project investment, progress, contract, cost, quality and other data for a project is very important, so the real estate project management in the design of information systems should take into account the system reliability and security.

\subsection{The Principle of Ease}

Taking into account the quality of personnel engaged in real estate management, they may have extensive experience in port management real estate items, but the computer and network applications may still inadequate, and therefore in the real estate development project management information system should be emphasis on the system so just the ease of use, user interface should be intuitive, unified style, operational procedures should be designed to meet the daily habits of the operator.

\subsection{The Principle of Portability}

Rapid development in information technology today, the real estate project development and application of management information systems should pay particular attention to the openness of the system, to support as many operating systems support multiple types of database systems, standards and norms as far as possible, to increase its versatility, the maximum for the user to save resources. Taking into account the common office systems with common software interface and professional in order to reduce the company's office expenses.

\subsection{Step by Step Implementation Principle}

Formation system is involved in the volume of information, more relevant departments, the implementation process more complex, and each enterprise management information system will also have focused on functional requirements, so to analyze reality, according to program functional requirements of high end to the step by step information systems.

\section{Conclusions}

The 21st century is knowledge economy, network economy era, business management information for enterprises to obtain a strong competition. Real estate business as part of information technology, project development and construction of its information technology, is bound to in the real estate business in this era brought huge economic benefits. Therefore, the use of management information systems as a real estate development and construction projects supporting enterprise management tools, will be brought to its good results.

Taking into account the real estate project management involves a wide range of large volumes of data, the implementation process is more complicated, this article only for real estate development company provides its construction project management information system functional architecture and implementation principles, but the development and maintenance of the system evaluation remains to be further studied.

\section{References}

Fang.J, Luo.S.P (2006). Study on Construction Project Variation Management System Design. Wuhan Oniversity of Technology Chinese Business Review.

Huang Feiyue(2004). Real Estate Enterprise Information and Core Comprehensiveness, Productivity.

Li Cunbin (2006), Chinese Construction Enterprise Information. Beijing: China Water Power Press.

Wang, X. T (2006). Construction project investment control model based on instant information. Journal of Harbin Institute of Technology.

Yang Dong(2005), Real Estate Project Management IS to Exlpore.

Zhao Bo(2004). Real estate digital management information system design and implementation. Guangzhou University of Science and Technology. 


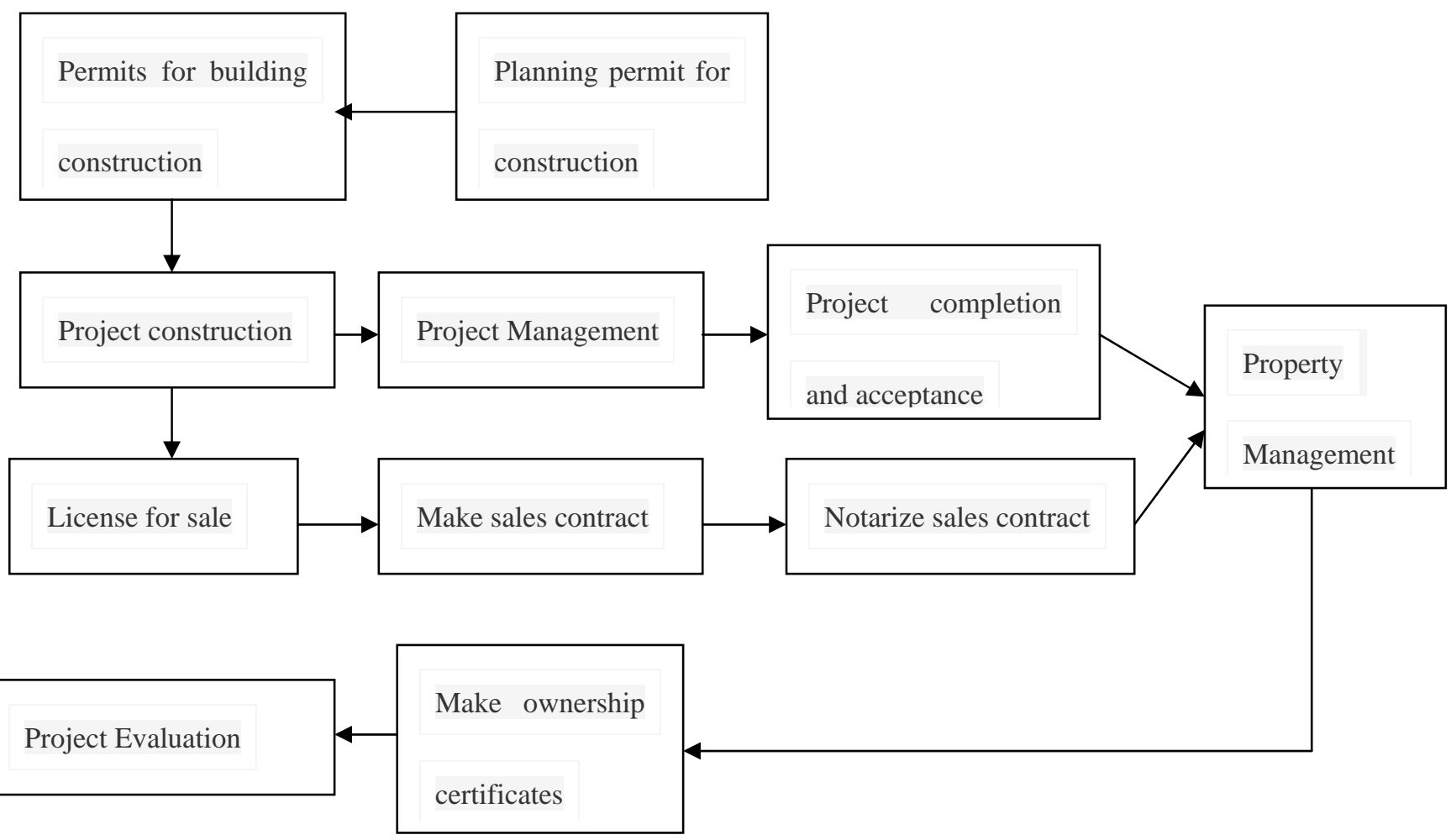

Figure 1. Flow Chart of Real Estate Construction Projects

\section{PMIS of real estate program}

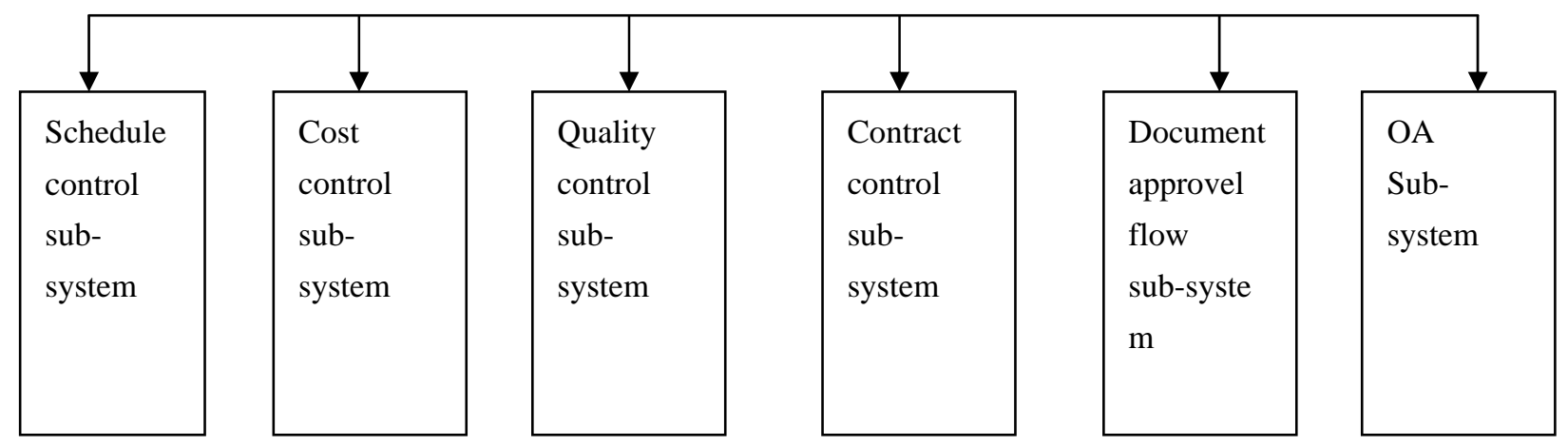

Figure 2. Real Estate Construction Project Management Information System Functional Architecture 